\title{
Standard Methods for Identifying the Microstructures of Iron Ore Sinters and Pellets*
}

\author{
By The 54th (Iron-making) Committee, Japan Society for the Promotion of Science**
}

\begin{abstract}
Synopsis
The present paper is to report on the methods for the identification of minerals in sinter which is jointly studied by the Iron-Making Committee of Japan Society for the Promotion of Science.

The object of this study was to establish the standard methods for the identification of major minerals contained in ordinary sinters and lime sinters and to find out whether these methods are applicable to the pellets or not. The minerals mainly studied in this work are $\alpha$-hematite, $\gamma$-hematite, magnetite, wustite, fayalite, calcium ferrites (binary and ternary), iron-gehlenite, lime-olivine, and calciferous magnetite.

Since appearance and colour play an important part for the identification of various minerals, the results obtained in the current study are mainly shown by photographs of typical structures.
\end{abstract}

\section{Introduction}

A subject, that is, how the microstructures of iron ore sinters were commonly identified and which method should be adopted as the standard method for the identification of microstructures, was mainly discussed at the 48th meeting of the 54th (Iron-Making) Committee of Japan Society for the Promotion of Science held in July, 1959. The conclusion arrived at in this meeting is as follows: up to present, the identification of microstructures has been mostly made by the colour of mineral, etching properties, hardness, etc. However, these methods were not satisfactory in the strict sense of accurate identification.

In order to establish an appropriate method for the identification of microstructures, the Sinter-Structure Sub-Committee of the 54th Committee was organized and first met on December 11, 1961. Since then, the meetings were repeatedly held thirteen times, and during which time an appropriate method for identifying sinter structure was established and the photographs of standard structures were selected by the committee. This paper reports on the experimental results obtained, the identification method established and the photographs of typical structures obtained by the Sub-Committee.

\section{Research}

Due to the fact that the ordinary sinter is mainly composed of iron oxides, a particular attention has been paid on the identification of three iron oxides, such as, hematite, magnetite, and wustite. These oxides can not easily be distinguished from their colour, therefore, the identification was mainly made by both etch test and microhardness measurement.

It was found that the combination method is also applicable to the pellets, the structure of which is chiefly composed of iron oxides similar to that of ordinary sinters.

Since the formation of calcium ferrites resulted from the mixing of lime stone is a special feature of lime sinter, a great effort has been paid to find the proper method for the identification of calcium ferrites. According to Snow ${ }^{1)}$ and Nyquist, ${ }^{2)}$ there are six kinds of calcium ferrites, as described later, and these calcium ferrites can be identified by etching with $\mathrm{HCl}$ or HF solution.

To ascertain the appropriateness of etching method for the identification of these calcium ferrites and also to know whether the results obtained by etching method are useful in discussing the structure of sinter or not, many experiments have been made for lime sinter by the members of the Sub-Committee.

However, the results obtained by the members from the following experiments, such as, the microscopic and X-ray tests on the calcium ferrites in the system of $\mathrm{CaO}-\mathrm{Fe}_{2} \mathrm{O}_{3}$, the microscopic observations after the etching test according to the method suggested by Snow as shown in Table 1 , and the hydrogen reduction tests by the use of specimens adding 5, 10, and $15 \%$ lime stone, respectively, prepared by a sintering

Table 1. Etching behaviour of calcium ferrite minerals $\left(\right.$ Snow $\left.^{1)}\right)$

\begin{tabular}{l|c|c|c}
\hline \multirow{2}{*}{ Mineral } & \multicolumn{4}{|c}{ Etching time (sec) } \\
\cline { 2 - 5 } & $\begin{array}{c}20 \% \mathrm{HCl} \\
\text { solution, } \\
70^{\circ} \mathrm{F}\end{array}$ & $\begin{array}{c}20 \% \mathrm{HCl} \\
\text { solution, } \\
140^{\circ} \mathrm{F}\end{array}$ & $\begin{array}{c}50 \% \mathrm{HCl} \\
\text { solution, } \\
140^{\circ} \mathrm{F}\end{array}$ \\
\hline $2 \mathrm{CaO} \cdot \mathrm{Fe}_{2} \mathrm{O}_{3}$ & 15 to 30 & - & - \\
$\mathrm{CaO} \cdot \mathrm{FeO} \cdot \mathrm{Fe}_{2} \mathrm{O}_{3}$ & No etch & 15 to 60 & - \\
$4 \mathrm{CaO} \cdot \mathrm{FeO} \cdot 4 \mathrm{Fe}_{2} \mathrm{O}_{3}$ &, & 15 to 60 & - \\
$3 \mathrm{CaO} \cdot \mathrm{FeO} \cdot 7 \mathrm{Fe}_{2} \mathrm{O}_{3}$ &, & No etch & 30 to 120 \\
$\mathrm{CaO} \cdot 2 \mathrm{Fe}_{2} \mathrm{O}_{3}{ }^{*}$ & $"$ &, & Slight etch \\
$\mathrm{CaO} \cdot \mathrm{Fe}_{2} \mathrm{O}_{3}$ &, &, & Very slight etch
\end{tabular}

* The presence of this mineral is confirmed by etching consisting of a 60 to $120 \mathrm{sec}$ exposure to $10 \% \mathrm{HF}, 40 \%$ water, and $50 \%$ alcohol solution after the etch in $50 \% \mathrm{HCl}$ at $140^{\circ} \mathrm{F}$.

* Presented at the 71st ISIJ Meeting, April, 1966 in Tokyo. Originally published in Tetsu-to-Hagané (Journal of The Iron and Steel Institute of Japan), 52 (1966), 249, in Japanese.

** Hitotsubashi, Kanda, Chiyoda-ku, Tokyo. This article was written by the following members :

Koji Sanbongi, Tohoku University

Yasuo Omori, Tohoku University

Teruo Ikeno, Technical Development Department, Fuji Iron \& Steel Co., Ltd.

Shojiro Watanabe, Central Research Laboratories, Sumitomo Metal Industries, Ltd.

Nobunao Nishida, Central Research Laboratory, Fuji Iron \& Steel Co., Ltd. 
pan in laboratory scale, did not agree very well one another. Nevertheless, it was found that there is a some correlation among the results if calcium ferrites are classified into binary and ternary systems, and also there is no significant difference in reducing properties of these specimens. The fact may indicate that the precise classification of calcium ferrites is not so important. Thus, methods for identifying binary and ternary calcium ferrites including a brief description of mineralogical characteristics of calcium ferrites were established as given in $\boldsymbol{I I I}-5$, Calcium Ferrite.

On the other hand, the use of super fluxed sinter becomes popular in industrial plants during this period of time. Different structure may be expected when the basicity of sinter is increased as in the case of super fluxed sinter. Therefore, additional experiments were made by using the sinters having basicity of 1.5, 2.0, and 2.5 , respectively, which were prepared with a sintering pan in laboratory scale. The results obtained for the low basicity sinters show that calcium ferrite is hardly formed when the basicity of sinter is less than 1.0. It was also observed that $\mathrm{CaO}$ is absorbed into slag of melilite in the form of iron-gehlenite. When the basicity is more than 1.0, the amounts of irongehlenite, slag, and hematite decrease as the basicity increases. On the contrary, the amounts of calcium ferrite, lime-olivine, and calciferous magnetite increase with increasing basicity. These structures are peculiar to the lime sinter, and seem to be closely related to the properties of lime sinter. Appropriate method for the identification of these structures was established and the photographs corresponding to these structures were prepared.

\section{Methods for the Identification of Sinter Struc- tures}

\section{General}

The method selected for the identification of sinter structures should be conveniently applied at workshop.

\section{Identification by the Microscopic Observation}

Reflection and transmission methods are used for the microscopic examination, however, the former is adequate for simple identification. The specimen for reflection type microscopic examination is made as follows: the sinter is either set in resin, or used as it is, then polished.

On the other hand, the laminate specimen for the transmission test is prepared as follows: the specimen is ground as the surfaces are parallel to each other. One side of the ground surfaces is then carefully polished on a glass plate, and glued on a slide glass with Canada balsam as the polished surface is faced to the glass plate. The glued specimen is polished until it becomes $0.03 \mathrm{~mm}$ thick, and then, it is covered with a slide glass.

3. Identification by Etch Test
The specimen used for the reflection microscopy is immersed into an etching solution contained in a small vessel such as evaporating dish, after the microscopic observation. The specimen is kept in the etching solution for a certain period of time, taken out from the solution, washed with running water or alcohol, ${ }^{*}$ dried with blowing air, and then subjected for the microscopic observation. Since the most of sinter is porous, etching reagent is easily remained in pores if the washing of specimen is not satisfactory. To avoid this inconvenience, a platinum wire having a small ring of about $2 \mathrm{~mm}$ dia. which is filled with etching reagent is frequently used to etch a small portion of the polished surface.

\section{Identification by Microhardness Measurement}

The microhardness measurements are made as a supplemental method for identification by the reflection microscopy. The specimen used for the reflection microscopy is used as the specimen of microhardness measurement. Microhardness is measured by the size of deformation which is traced with a diamond drill under a load of about 100 to $200 \mathrm{~g}$. The structure is then identified from the microhardness obtained. The specimen used for the microhardness measurement should be taken out from the sample of considerably less amount of cracks.

\section{Properties of Mineral}

\section{$\boldsymbol{\alpha}$-hematite $\left(\boldsymbol{\alpha}-\mathrm{Fe}_{2} \mathrm{O}_{3}\right.$}

Optical properties: hematite belongs to hexagonal system and the refractive index of hematite $(\mathrm{No}=3.22)$ is very high. It is the brightest among the minerals found in sinter, and shows greyish white colour with a bluish tint. Hematite can be distinguished from magnetite and wustite because of the reflection polarization. Generally, recrystallization of hematite proceeds almost homogeneously and a great number of small crystals are formed by recrystallization. These small crystals grow into large crystals by fusion.

Hematite formed in iron ore sinter including the hematite formed by reoxidation often displays crystal habits, such as, needlelike, platy, or polygonal structures (triangle to hexagon). It shows reddishbrown colour under transmitted light.

Etching properties: Hematite cannot be etched by Aqua Regia ( 3 parts of $\mathrm{HCl}$ : 1 part of $\mathrm{HNO}_{3}$ ). However, magnetite and wustite are etched satisfactory and show yellow and black colour, respectively.

Microhardness: In the cases that the structure of hematite is extremely large and extend beyond the visual field of microscope and that the identification of microstructure is difficult because of fine grains, the measurements of microhardness give a valuable informations for the identification of microstructure because the microhardness of hematite is about 1000 $\mathrm{HV}$ which is the highest among the iron oxides. 
$\boldsymbol{\gamma}$-hematite $\left(\boldsymbol{\gamma}-\mathrm{Fe}_{2} \mathrm{O}_{3}\right)$

Optical properties of $\gamma$-hematite are quite similar to those of $\alpha$-hematite, except the isotropic property. Corrosion properties and microhardness are also similar to those of $\alpha$-hematite.

\section{Magnetite $\left(\mathrm{Fe}_{3} \mathrm{O}_{4}\right.$}

Optical properties: Magnetite belongs to cubic system and the refractive index, N, is 2.42. The colour of magnetite is grey with brownish tint and the reflection brightness is comparatively low as compared with the others. Since the magnetite shows no polarization property and the comparatively low refractivity, it can be clearly distinguished from hematite. In general, magnetite exists in the form of massive crystals of irregular shape. It is frequently crystallized in the form of dendrite, tetrahedron, or octahedron, etc. Due to these particular crystallographic properties as mentioned above, it is clearly distinguished the magnetite from the other iron oxides. In addition, magnetite is opaque under transmitted light.

Etching properties: Magnetite turns to yellow in Aqua Regia, but hematite does not change in the same reagent. On the other hand, in ethylalcohol saturated with $\mathrm{SnCl}_{2}$, ${ }^{*}$ wustite changes to dark grey colour when it is etched for about 1 to $2 \mathrm{~min}$, but not magnetite. Magnetite can therefore be clearly distinguished from hematite and wustite by their etching properties.

\section{Wustite (FeO}

Optical properties: Wustite belongs to cubic system and shows isotropic property. There is no remarkable difference in optical properties between wustite and magnetite. However, wustite shows a little lower refractive index and a slightly dark colour as compared with magnetite. In general, wustite exists in granular or dendritic forms and is often observed as in the form of eutectic with magnetite. However, it is difficult to distinguish the wustite from other iron oxides due only to the optical properties. Wustite is opaque under transmitted light as in the case of magnetite.

Etching properties: Among the methods used for the identification of wustite, etch test is the most reliable and accurate method. Wustite can be distinguished from magnetite because it is etched completely or almost completely in an aqueous solution saturated with $\mathrm{SnCl}_{2}$ for about 1 to $2 \mathrm{~min}$ exposure.

Microhardness: Wustite in sinter generally forms an eutectic with magnetite, therefore, it shows a slightly lower microhardness, ranging from 450 to $500 \mathrm{HV}$, than that of magnetite.

\section{Fayalite $\left(\mathrm{Fe}_{2} \mathrm{SiO}_{4}\right)$}

Optical properties: Fayalite belongs to orthrombic system and shows the reflective polarization. The refractive index of fayalite $(\mathrm{Ng}=1.886)$ is lower than those of other iron oxides mentioned above, but comparatively higher than the other silicates found in the matrix. Fayalite in sinter frequently crystallizes in the form of long and thin lathy type crystals. In case that the fayalite exists in the characteristic crystal form, it can be easily distinguished from other minerals. Under transmitted light, it is colourless in the case of parallel nicols but light-yellow, yellow-green, or orange colour for the case of crossed nicols.

Microhardness: The values of microhardness are ranging from 600 to $700 \mathrm{HV}$

\section{Calcium Ferrite**}

Optical properties: Calcium ferrite shows the optical anisotropy. General crystal form of calcium ferrite is rectangular, but it is occasionally crystallized in irregular shapes, such as, massive, needlelike, or dendritic forms. Colour of the crystal is grey with greenish or bluish tint under reflected light. The reflectivity of calcium ferrite is higher than those of silicates in matrix but lower than magnetite. Calcium ferrite can easily be distinguished from silicates by these characteristic crystallographic properties. Under transmitted light, calcium ferrite is reddish orange in the case of parallel nicols, however, the rectangular crystal shows straight distinction. The colour of hematite is also red as already mentioned in the previous section, but it is the dark red of pleochroism. On the other hand, fayalite is colourless in the case of parallel nicols. Therefore, it can easily be distinguished calcium ferrite from hematite and fayalite.

Etching properties: The etching properties of calcium ferrites are depending on the state of combination between lime and iron oxide. Calcium ferrites are mostly soluble in $\mathrm{HCl}$ or $\mathrm{HF}$, so it can easily be identified from other iron oxides. The etching reagents commonly used are as follows:

$\mathrm{HCl}(1: 4)$ (1 part of concentrated $\mathrm{HCl}$ and 4 parts of water ; time of exposure: not more than $30 \mathrm{sec}$ at room temperature).

$\mathrm{HCl}(1: 1)$ (1 part of concentrated $\mathrm{HCl}$ and 1 part of water ; time of exposure: not more than $2 \mathrm{~min}$ at $60^{\circ} \mathrm{C}$ )

$\mathrm{HF}+$ alcohol $(1: 4: 5)$ (1 part of hydrofluoric acid $(\mathrm{HF}>$ $46.0 \%$ ), 4 parts of water, and 5 parts of ethylalcohol; time of exposure: not more than $2 \mathrm{~min}$ at room temperature)

Among calcium ferrites, only $\mathrm{CaO} \cdot \mathrm{Fe}_{2} \mathrm{O}_{3}$ is not etched by any of the etching reagents mentioned above. The other calcium ferrites are etched by either one or more of the above reagents. Particularly, $2 \mathrm{CaO}$. $\mathrm{Fe}_{2} \mathrm{O}_{3}$ is easily etched with $\mathrm{HCl}(1: 4)$ solution and the colour of $2 \mathrm{CaO} \cdot \mathrm{Fe}_{2} \mathrm{O}_{3}$ becomes black when it is etched in this reagent. Calcium ferrites in ternary system, such as, $\mathrm{CaO} \cdot \mathrm{FeO} \cdot \mathrm{Fe}_{2} \mathrm{O}_{3}, 4 \mathrm{CaO} \cdot \mathrm{FeO} \cdot 4 \mathrm{Fe}_{2} \mathrm{O}_{3}$, and $3 \mathrm{CaO} \cdot \mathrm{FeO} \cdot 7 \mathrm{Fe}_{2} \mathrm{O}_{3}$ can be etched with $\mathrm{HCl}(1: 1)$

* An aqueous solution saturated with $\mathrm{SnCl}_{2}$ containing $1 \% \mathrm{HCl}$ in water may also be used instead of ethylalcohol saturated with $\mathrm{SnCl} \mathrm{I}_{2}$.

** Calcium ferrites are classified as follows :

1. Calcium ferrites in binary system : $\mathrm{CaO} \cdot 2 \mathrm{Fe}_{2} \mathrm{O}_{3}, \mathrm{CaO} \cdot \mathrm{Fe}_{2} \mathrm{O}_{3}, 2 \mathrm{CaO} \cdot \mathrm{Fe}_{2} \mathrm{O}_{3}$.

2. Calcium ferrites in ternary system : $3 \mathrm{CaO} \cdot \mathrm{FeO} \cdot 7 \mathrm{Fe}_{2} \mathrm{O}_{3}, \mathrm{CaO} \cdot \mathrm{FeO} \cdot \mathrm{Fe}_{2} \mathrm{O}_{3}, 4 \mathrm{CaO} \cdot \mathrm{FeO} \cdot 4 \mathrm{Fe}_{2} \mathrm{O}_{3}, \mathrm{CaO} \cdot 3 \mathrm{FeO} \cdot \mathrm{Fe}_{2} \mathrm{O}_{3}$. 
solution.

Microhardness: 800 to $900 \mathrm{H} . \mathrm{V}$. (between the values of hematite and magnetite).

Iron Gehlenite $\left(\mathrm{Ca}_{2}\left(\mathrm{Fe}^{3+}, \mathbf{A l}\right)_{2} \mathbf{O}_{7}\right.$

Optical properties: Iron gehlenite belongs to tetragonal system, and it is mainly crystallized from glass in the dendritic form. Brightness of iron gehlenite is more than glassy slag but less than calcium ferrite under reflected light. On the other hand, it shows a pleochroism of green-yellowish brown under transmitted light and the refractive index is considerably high (iron gehlenite shows $\mathrm{No}=1.726, \mathrm{Ne}=$ 1.723 in end member $\left.\mathrm{Ca}_{2}\left(\mathrm{Fe}^{3+}, \mathrm{Al}\right){ }_{2} \mathrm{SiO}_{7}\right)$.

Etching properties: Since the glassy slag surrounding the iron gehlenite crystal is more rapidly etched by $\mathrm{HCl}(1: 1)$ solution, the characteristic yellowish-brown colour of iron gehlenite is observed as internal reflection.

Lime Olivine $\left(\gamma-\mathrm{Ca}_{2} \mathrm{SiO}_{4}\right.$

Optical properties: Lime olivine belongs to orthrombic system, and it exists in the form of thin and rectangular crystal. The crystal is colourless and shows straight extinction under transmitted light. The refractive index and double refraction of lime olivine are considerably lower than those of calcium ferrites, but slightly higher than those of iron gehlenite $(\mathrm{Np}=1.717, \mathrm{Ng}=1.735, \mathrm{Ng}-\mathrm{Np}=0.018)$.

\section{Calciferous Magnetite ( $\mathrm{Fe}, \mathrm{Ca}) \mathrm{Fe}_{2} \mathrm{O}_{4}$}

Optical properties: The optical properties are similar to those of magnetite.

Etching properties: It can be clearly distinguished from magnetite, because many linear etched lines parallel to $\{111\}$ are observed when it is etched in $\mathrm{HCl}(1: 1)$ solution.

\section{Photographs of Structure}

Typical photographs representing the structures of sinter, pellet, and lime sinter are selected in order to use as the references of the methods mentioned above. Since the typical photographs selected by the members are to be published shortly by the 54th (Iron-Making) Committee of Japan Society for the Promotion of Science, some of them are only inserted in this report.

\section{Structure of Lime Free Sinter}

Most of the test specimens used in the current work were made at each steel mill with a sintering pan in laboratory scale. The rate of mixing for the preparation of sinter and the sintering conditions were, therefore, not entirely the same for all specimens. Therefore, the following classification of sinter structures has been chosen as a matter of convenience, and the photographs are illustrated for each group.

(1) Structure which is observed when hematite is used as the material of sinter and consisted mainly of diffusion combination of slightly burnt hematite.

(2) Structure in which hematite and magnetite co-exist.

\footnotetext{
(i) Massive hematite

(ii) Platy hematite

(iii) Hematite and magnetite are irregular but not polygonal form.
}

(3) Reoxidized structure of magnetite.

(4) Structure of which the core of crystal grain is consisted of hematite and the surroundings are magnetite.

(5) Dendritic and skeletal magnetite which is not included in the groups (1)-(4).

(6) Structure in which wustite and magnetite are co-existed or in the form of eutectic.

(7) Structure in which fayalite and magnetite coexist.

(8) Structure in which fayalite, magnetite, and wustite co-exist.

(9) Thin section sample of fayalite and magnetite.

Unfortunately, it was not able to obtain the photographs representing the structures mentioned in the groups of (1)-(4).

Photo. 1-(a) represents the structure of group (2)-(i)
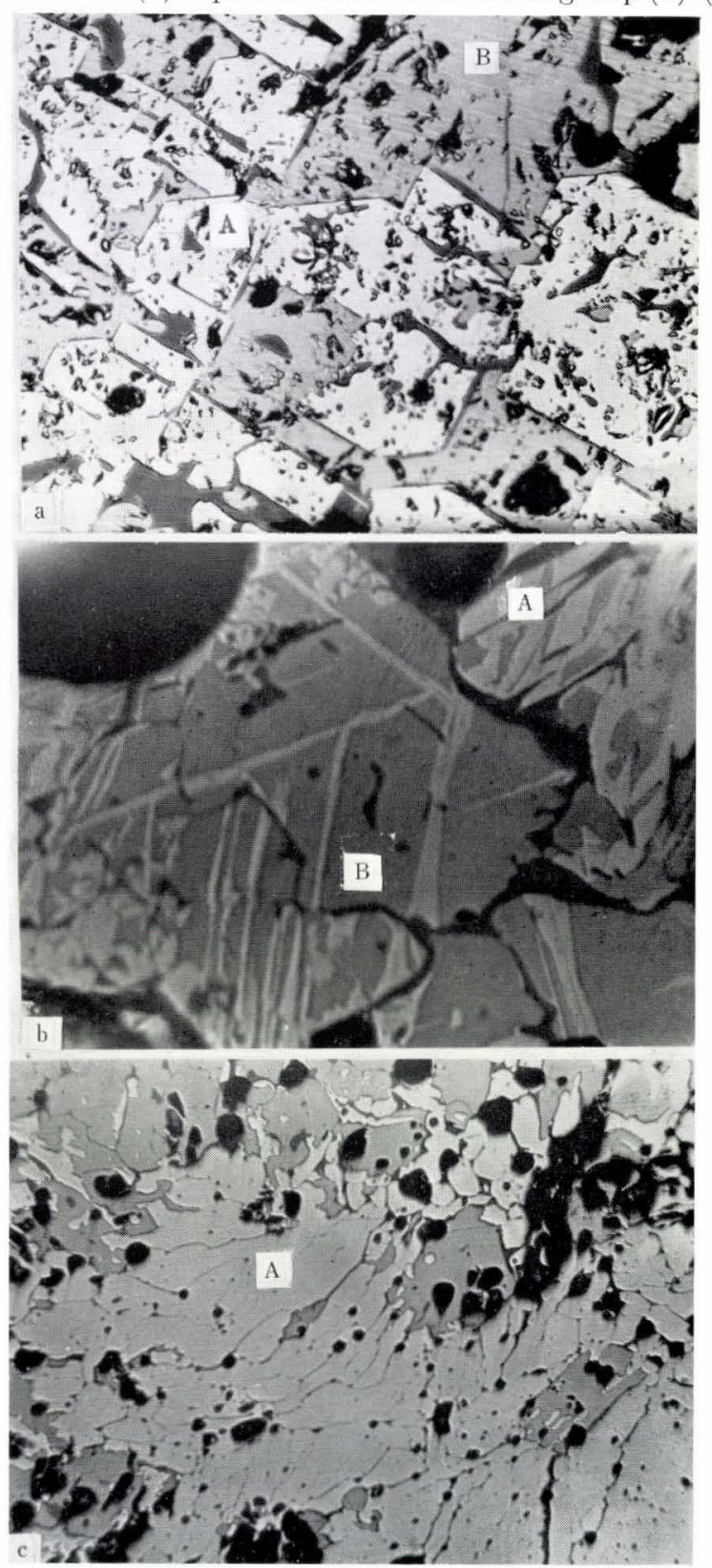

A: hematite

B: magnetite

Photo. 1. Microstructures of hematite and magnetite (a), (b): $(\times 400)(7 / 8), \quad(c):(\times 100)(7 / 8)$ 
and shows that the massive hematite and magnetite co-exist. Photo. 1-(b) is corresponding to the group (2)-(ii), and shows that the platy hematite is co-existing in the magnetite grain. As shown in Photo. 1-(c) which corresponds to the group (2)-(iii), the forms of hematite and magnetite are irregular. Photo. 2-(a) shows the structure formed by reoxidation occured during the cooling period of the sintering process. Such a structure, which is corresponding to the group (3), is often observed around the pore, and shows that the circumference of magnetite is reoxidized to hematite. In many cases, the magnetite observed in iron ore sinter shows special forms such as dendritic or skeletal forms. Photo. 2-(b), which is corresponding to the group (5), shows the structure of magnetite in dendritic or skeletal form. Photo. 3-(a) and -(b) show structures in which wustite and magnetite coexist. The wustite observed in these photographs shows the spherical form. For the most cases, fayalite exists in the part such that the wustite of spherical form is observed, and therefore, the structure of these photographs corresponds to the groups (6) and (8). Photo. 4 shows the structure in which magnetite and fayalite co-exist. Magnetite is crystallized in the matrix of fayalite. This is a typical sinter structure and corresponds to the group (7). Photo. 5-(a) and -(b) show the structure, in which fayalite and magnetite co-exist, taken under reflected and transmitted lights.

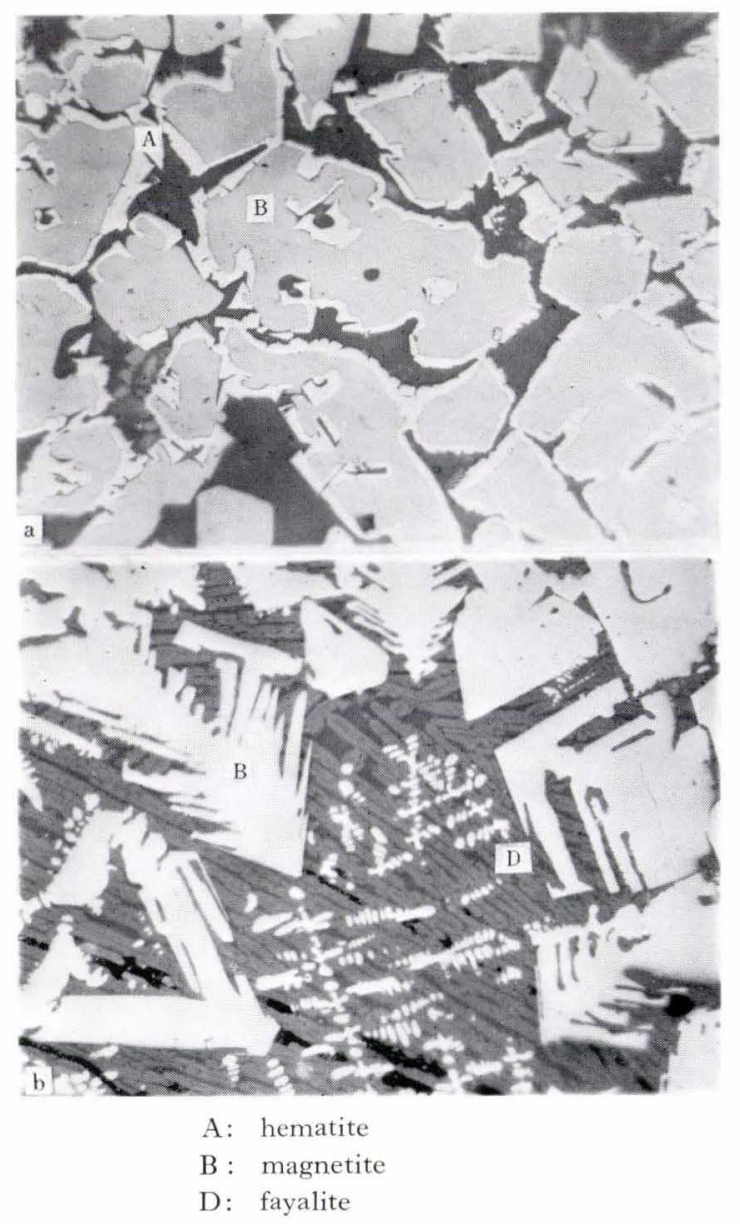

Photo. 2. Microstructure of magnetite (a), (b): $(\times 400)(7 / 8)$

\section{Photographs of Pellet Structure}

In order to know whether the methods used for the identification of sinter structures are also applicable to the identification of pellet structures or not, investigations have been made by using the following six different types of pellet: Robe River, Republic, Erie, Marcona, and Kawasaki.

The structures of pellet were at first identified in accordance with the methods mentioned above, and then, photographs were taken and selected as the references.

In this study, the photographs are taken in three

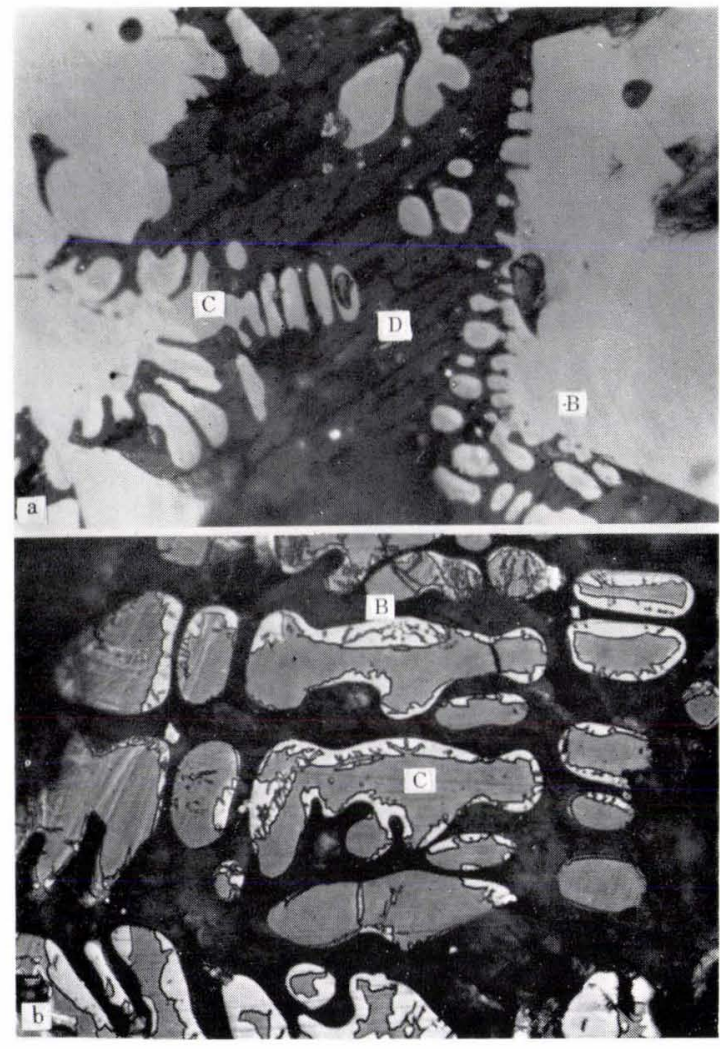

$$
\begin{array}{ll}
\text { B : magnetite } \\
\text { C: } \\
\text { D: faystite } \\
\text { falite }
\end{array}
$$

Photo. 3. Microstructures of magnetite, wustite, and fayalite. (a): $(\times 800)(7 / 8), \quad($ b): $\quad(\times 1000)(7 / 8)$

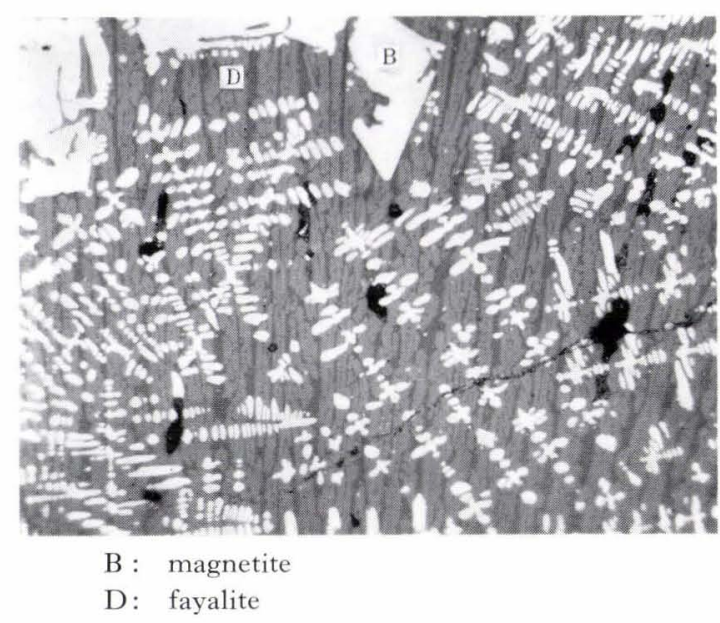

Photo. 4. Microstructures of magnetite and fayalite $(\times 400)(7 / 8)$ 
different parts of the pellet, that is, central intermediate and outer parts of the pellet. These photographs indicate that the methods mentioned above can also be used for the identification of pellet structure as in the case of sinter.

\section{Photographs of Lime-Sinter Structure}

Test specimens were prepared by $250 \mathrm{~kg}$ test pan of Yawata Steel's Technical Research Institute. Mixing ratio was coke $4.5 \%$ and return fine $30 \%$. The amount of lime stone added and the results of chemical analysis of sinter are shown in Table 2.

\section{Calcium Ferrites in Binary System}

Since the calcium ferrite in the form of $2 \mathrm{CaO} \cdot \mathrm{Fe}_{2} \mathrm{O}_{3}$ exists in the form of slightly round and massive crystal, and shows darker colour than the other binary calcium ferrites as shown in Photo. 6-(a), it can be easily

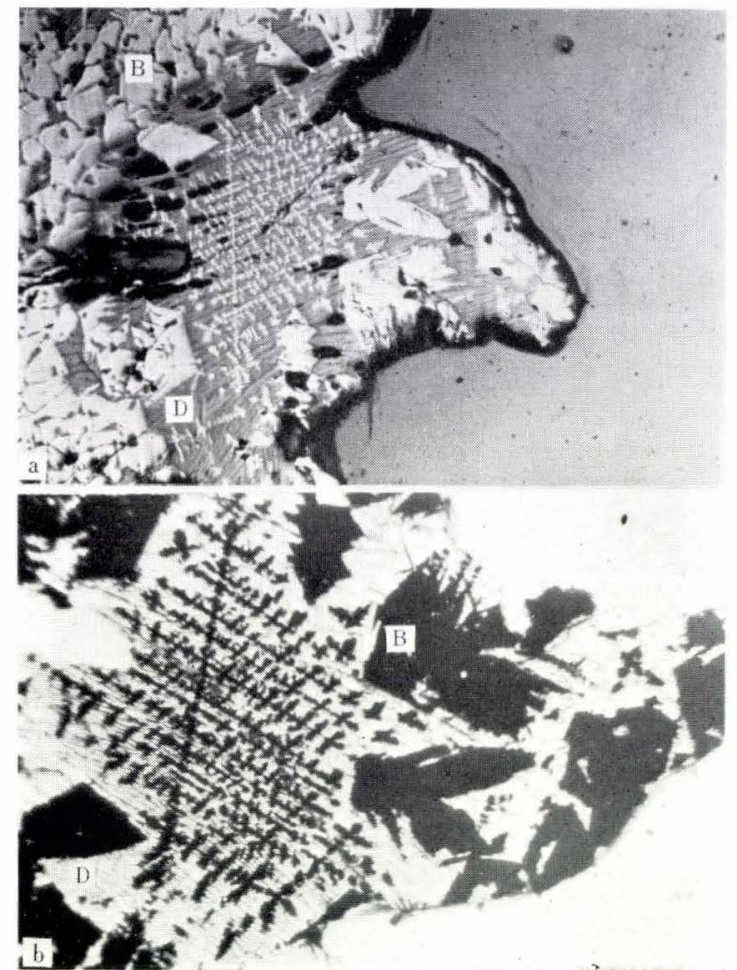

B : magnetite

D: fayalite

Photo. 5. Microstructures of magnetite and fayalite (a), (b): $(\times 100)(7 / 9)$ distinguished from the others. In addition, it is satisfactory etched with dil. $\mathrm{HCl}(1: 4)$ for the exposure less than $30 \mathrm{sec}$ and the colour changes to black by etching. On the other hand, calcium ferrite in the form of $\mathrm{CaO} \cdot \mathrm{Fe}_{2} \mathrm{O}_{3}$ can be identified to some extent from the crystal habit, such as, rectangular form and light colour. To distinguish $2 \mathrm{CaO} \cdot \mathrm{Fe}_{2} \mathrm{O}_{3}$ accurately from $\mathrm{CaO} \cdot \mathrm{Fe}_{2} \mathrm{O}_{3}$, it is desirable to use the other methods simultaneously, such as the analysis by means of an electron probe microanalyser.

\section{Calcium Ferrites in Ternary System}

All of the calcium ferrites in ternary system are etched by dil. $\mathrm{HCl}(1: 1)$ for the exposure less than $2 \mathrm{~min}$ at $60^{\circ} \mathrm{C}$. Straight or meandering lines, or both

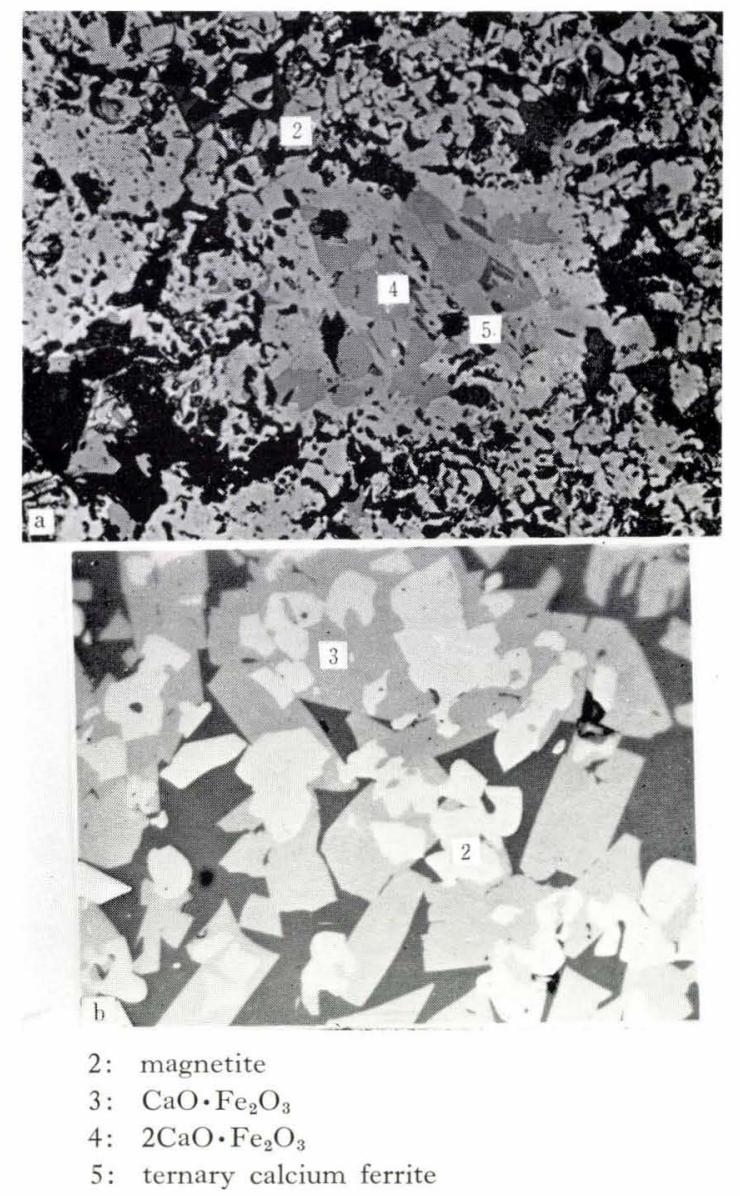

Photo. 6. Microstructure of binary calcium ferrite (no etched). (a), (b): $(\times 400)(7 / 8)$

Table 2. Chemical analysis of sinters

\begin{tabular}{|c|c|c|c|c|c|c|c|c|c|}
\hline Series & $\begin{array}{c}\text { Sample } \\
\text { No. }\end{array}$ & $\begin{array}{c}\text { Lime stone in } \\
\text { raw mixture } \\
(\%)\end{array}$ & $\begin{array}{c}\text { Set value of } \\
\text { basicity } \\
\left(\mathrm{CaO} / \mathrm{SiO}_{2}\right)\end{array}$ & $\mathrm{T} . \mathrm{Fe}$ & $\mathrm{FeO}$ & $\mathrm{Al}_{2} \mathrm{O}_{3}$ & $\mathrm{SiO}_{2}$ & $\mathrm{CaO}$ & $\mathrm{CaO} / \mathrm{SiO}_{2}$ \\
\hline \multirow{3}{*}{ I } & 1 & 5 & - & 58.27 & 13.18 & 3.70 & 6.60 & 5.73 & 0.87 \\
\hline & 2 & 10 & - & 57.22 & 11.83 & 3.68 & 6.84 & 6.97 & 1.02 \\
\hline & 3 & 15 & - & 55.18 & 10.93 & 3.70 & 7.04 & 9.22 & 1.31 \\
\hline \multirow{4}{*}{ II } & 4 & 9 & $1.5 \mathrm{~A}$ & 57.74 & 12.69 & 2.41 & 5.20 & 8.11 & 1.56 \\
\hline & 5 & 13 & $2.0 \mathrm{~A}^{*}$ & 55.95 & 12.69 & 2.63 & 5.32 & 10.38 & 1.95 \\
\hline & 6 & 8 & $2.0 \mathrm{~B}^{*}$ & 57.02 & 14.06 & 3.85 & 3.90 & 8.17 & 2.09 \\
\hline & 7 & 17 & $2.5 \mathrm{~A}$ & 54.89 & 12.53 & 2.31 & 5.22 & 12.35 & 2.37 \\
\hline
\end{tabular}

* $\mathrm{A}$ and $\mathrm{B}$ show the different level of $\mathrm{SiO}_{2} \%$. 
of them, are formed when it is etched with dil. $\mathrm{HCl}$, as shown in Photo. 7-(a) and -(b).

\section{Iron Gehlenite}

Photo. 8-(a) and -(b) show the dendritic structure of iron gehlenite which can be observed under transmitted and reflected lights, respectively. In general, the iron gehlenite does not co-exist with calcium ferrite, therefore the amount of iron gehlenite in the specimen containing $15 \%$ lime is much less than that of the specimen of 5\% lime as shown in Table 2 .

\section{Lime Olivine}

Lime olivine is generally observed in the specimen of high basicity. Considerably more amount of lime olivine is observed in the specimen $2.0 \mathrm{~A}$ as compared with the specimen $2.0 \mathrm{~B}$ which is containing less amount of $\mathrm{SiO}_{2}$ than the specimen $2.0 \mathrm{~A}$. The reason is mainly due to that a considerable amount of lime should be added to maintain the high basicity when the content of $\mathrm{SiO}_{2}$ in the sinter is high. (Photo. 9)

\section{Calciferous Magnetite}

The amount of calciferous magnetite increases with increasing basicity. It mainly exists in such a form as the calciferous magnetite is surrounded by calcium ferrite, as shown in Photo. 10.

The following minerals, free lime and hedenbergite are not included in the identification methods presented in this paper, because of their extremely rare existances in the sinters. However, their photographs were also inserted as the references.

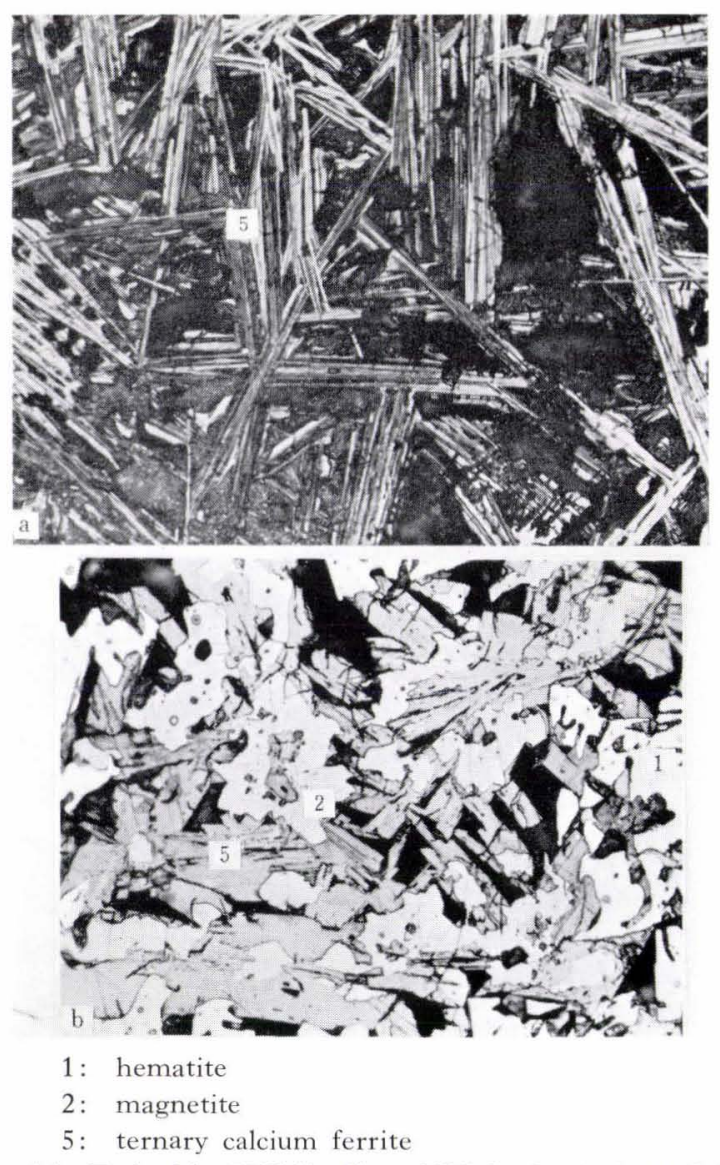

(a) Etched by $\mathrm{HCl}(1: 1)$ at $60^{\circ} \mathrm{C}$ for $2 \mathrm{~min}(\times 400)(7 / 8)$

(b) Etched by $\mathrm{HCl}(1: 1)$ at $60^{\circ} \mathrm{C}$ for $1 \mathrm{~min}(\times 400)(7 / 8)$

Photo. 7. Microstructure of ternary calcium ferrite

\section{Free Lime}

Free lime may exist in the following two cases:

(1) remains as a dissociation product of lime stone.

(2) crystallizes out from slag after it is dissolved as a slagging component.

From the results obtained, it was found that extremely small amounts of free lime of type (1) is only observed when the basicity is more than 2.0, but not for the specimens of less basicity. Generally, the free

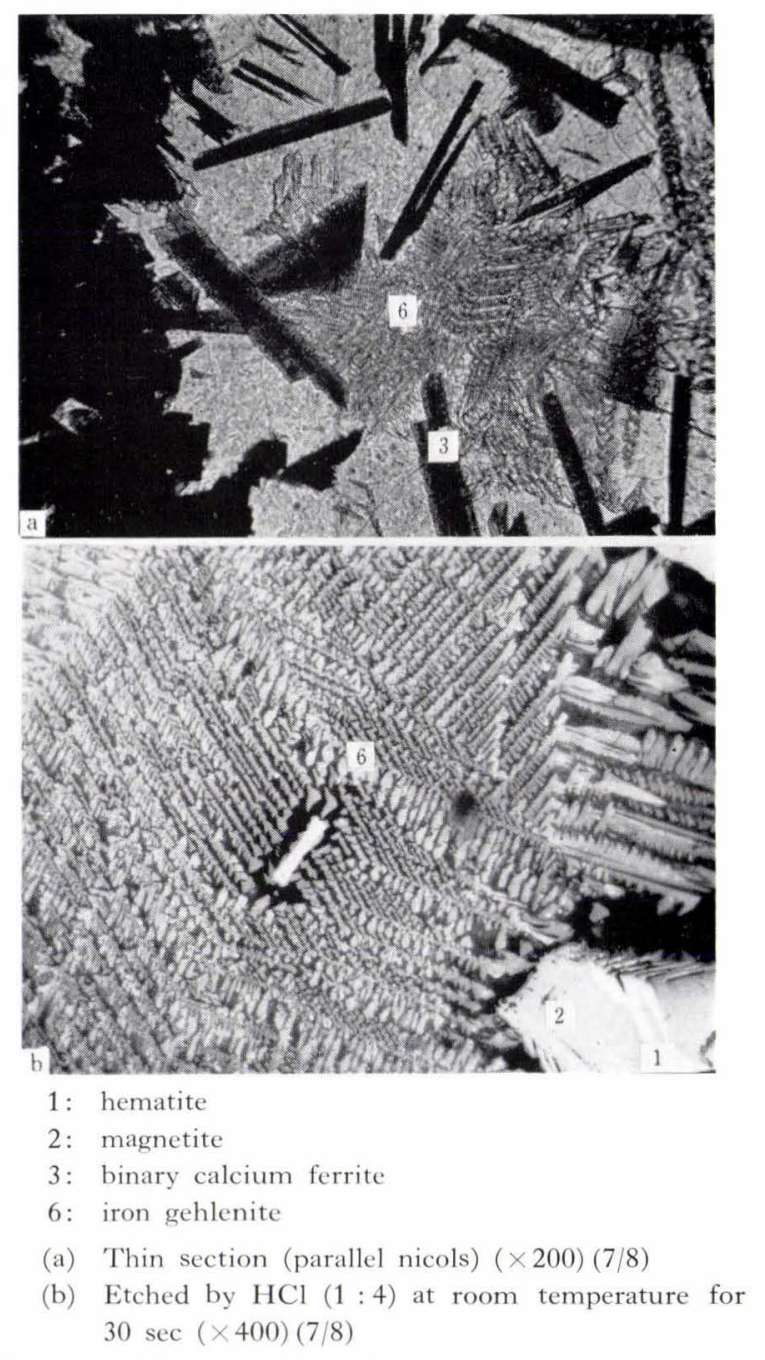

Photo. 8. Microstructure of iron gehlenite

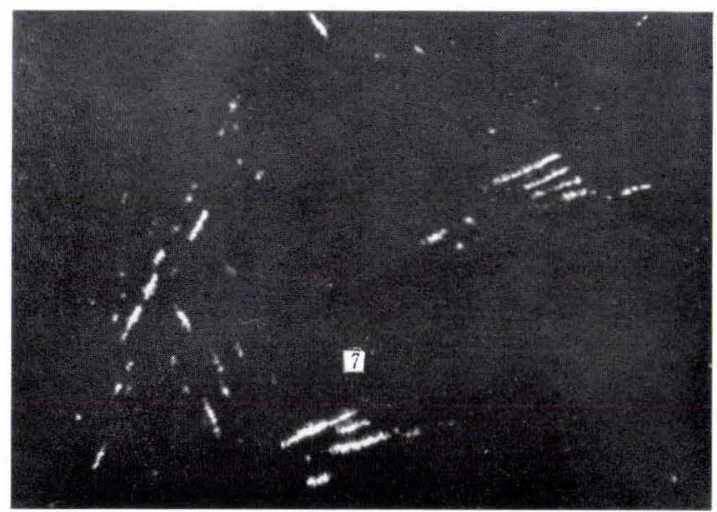

7: lime olivine

Photo. 9. The section of lime olivine (closed nicols) $(\times 80)(7 / 8)$ 


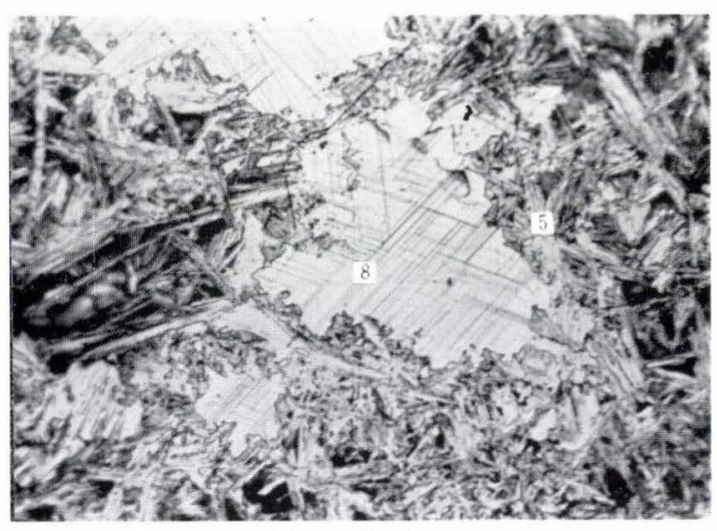

5: ternary calcium ferrite

8: calciferous magnetite

Photo. 10. Microstructures of calciferous magnetite and ternary calcium ferrite (etched by $\mathrm{HCl}(1: 1)$ at $60^{\circ} \mathrm{C}$ for $\left.1.5 \mathrm{~min}\right)(\times 400)(7 / 8)$

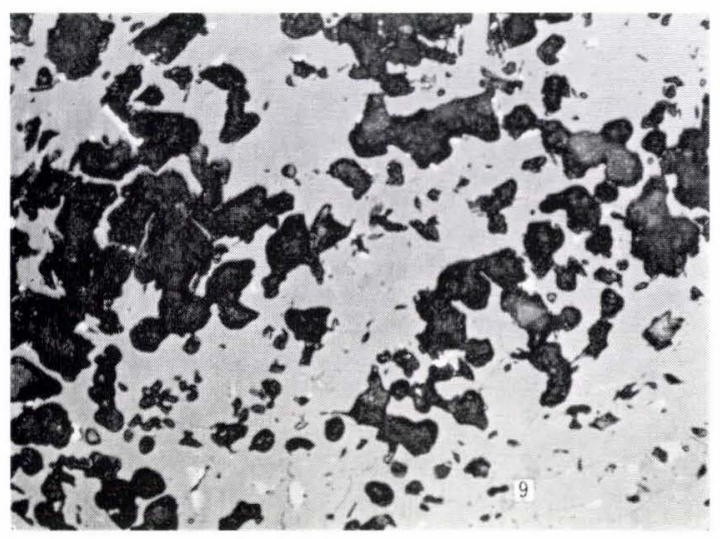

9: free lime

Photo. 11. Microstructure of free lime $(\times 400)(7 / 8)$

lime is bluish and massive, as shown in Photo. 11. Reflectivity of free lime is slightly lower and the colour is more dark than those of calcium ferrites.

\section{Hedenbergite $\left(\mathrm{CaFeSi}_{2} \mathrm{O}_{6}\right)$}

Under transmitted light, the thin hedenbergite crystal shows pleochroism of green-yellow, green or brownish green, and oblique distinction. The amount of hedenbergite formed in the sinter seems to vary depending on the degree of oxidation of sinter. However, a small amount of hedenbergite was only ob- served for the standard specimens in which the basicity is 2.5 .

\section{Acknowledgements}

Progress of joint research, the methods established for the identification of microstructures and the photographs of typical structures of sinter selected by the Sinter-Structure Sub-Committee, the 54th Committee of Iron-Making, Japan Society for the Promotion of Science are reported in this paper.

The author wishes to thank the following members of the Sinter Structure Sub-Committee who carried out the present research :

\begin{tabular}{|c|c|c|}
\hline Koji Sanbongi & Chairman & Tohoku University \\
\hline Teinosuke Yagi & Member & Kyushu University \\
\hline Takahiro Morimune & , & Toyama University \\
\hline Chikao Yoshii & , & Hokkaido University \\
\hline Michio Inoue & , & Nagoya University \\
\hline Akitoshi Ishimitsu & ", & $\begin{array}{l}\text { Technical Research Insti- } \\
\text { tute, Yawata Iron \& Steel } \\
\text { Co., Ltd. }\end{array}$ \\
\hline Teruo Ikeno & ", & $\begin{array}{l}\text { Technical Development } \\
\text { Dept., Fuji Iron \& Steel } \\
\text { Co., Ltd. }\end{array}$ \\
\hline Yoshikazu Takahashi & , & $\begin{array}{l}\text { Central Technical Re- } \\
\text { search Laboratory, Fuji } \\
\text { Iron \& Steel Co., Ltd. }\end{array}$ \\
\hline Shojiro Watanabe & , & $\begin{array}{l}\text { Central Research Labora- } \\
\text { tories, Sumitomo Metal } \\
\text { Industries, Ltd. }\end{array}$ \\
\hline Kazuo Kunii & , & $\begin{array}{l}\text { Central Research Institute, } \\
\text { Kobe Steel, Ltd. }\end{array}$ \\
\hline Takeshi Hamada & ", & Chiba Research Institute, \\
\hline$\cdots$ & & $\begin{array}{l}\text { Chiba Works, Kawasaki } \\
\text { Iron \& Steel Corp. }\end{array}$ \\
\hline Haruo Adachi & , & $\begin{array}{l}\text { Technical Research Insti- } \\
\text { tute, Nippon Kokan K.K. }\end{array}$ \\
\hline Nobunao Nishida & Secretary & $\begin{array}{l}\text { Central Technical Re- } \\
\text { search Laboratory, Fuji } \\
\text { Iron \& Steel Co., Ltd. }\end{array}$ \\
\hline Shiro Banya & , & Tohoku University \\
\hline Yasuo Omori & , & Tohoku University \\
\hline
\end{tabular}

\section{REFERENCES}

1) R. B. Snow: Proc. AIME Blast Furnace, Coke Oven and Materials, (1960).

2) O. Nyquist: Agglomeration, (1962), 809, (Interscience Publishers). 